\title{
DESIGNING AND INSTALLATION OF LOW-COST OPTIMIZED WIND MONITORING SYSTEM
}

\author{
Saurav Gupta ${ }^{1}$, Gagandeep Kaur ${ }^{2}$ \\ ${ }^{1}$ Department of Electrical \& Instrumentation engineering, Thapar University, Patiala, India \\ ${ }^{2}$ Department of Electrical \& Instrumentation engineering, Thapar University, Patiala, India
}

\begin{abstract}
Measurement of wind parameters is a necessity for chemicals industry. A big disaster can be prevented from happening if accurate wind monitoring system is installed in the industry. It is not easy to buy and install a wind monitoring system for every chemical industry from a vendor since its price is high and design varies from company to company and process to process. To make life easier, better and safer, a low cost optimized wind monitoring system has been designed and installed here with available resources. This project will help in measuring wind speed, wind direction and ambient air temperature to take protective measure right before the havoc, so that it can be prevented.
\end{abstract}

Keywords: anemometer, wind vane, RTD, gill shield, reference point ****

\section{INTRODUCTION}

Wind monitoring system has become a necessity of daily life in industries, especially in a chemical industry where there is always a danger of fire, or some poisonous gas leakage into the atmosphere. At that time safety of personnel is as important as the value of material leaked.

With emerging chemical industries risk has increased many folds, and due to high cost of wind monitoring system, many of small industrialists prefer to rely upon big industries for weather data, though it changes from place to place.

Sensors have become one of the essential parts of daily life as in mobiles, televisions, laptops etc. It also forms the major and important part of process industries for automation of valves. These are used in wind monitoring system for measurement of wind speed, wind direction and its temperature.

A device consist of various sensors, that could be taken out and used for various other purpose when a device can no longer be repaired and perform its requisite function. This will not only save money but will help engineer to gain knowledge of the components, and here it will save many lives as well.

\section{TYPE OF INSTRUMENTS USED}

Wind monitoring system here consists of three basic parts 4 cup wind anemometer (wind speed), Light weight wind vane (wind direction) and temperature probe (ambient air temperature).

\subsection{Four Cup Wind Anemometer}

Four cup anemometer (e.g. Fig. 3) is used for measuring the near-horizontal wind speed. It consists of light weight but rugged 4- plastic cups (taken from a plastic ball) mounted on a vertical shaft, with the help of aluminum rods placed at right angles (e.g. Fig. 1).Vertical shaft is mounted on low friction bearings. One of the cups always faces the oncoming wind, which with the help of specifically designed aerodynamic cups convert wind force to torque that in turn rotates the shaft. The other end of the shaft rotates a round magnet. A reed switch (transducer) placed near the magnet makes the contact closure twice per revolution of the rotor. Thus reed switch helps in converting rotational motion to electrical pulses. A cover rotates with the rotor at top to prevent the rotor from ill effects of dust and rain (e.g. Fig. 2).

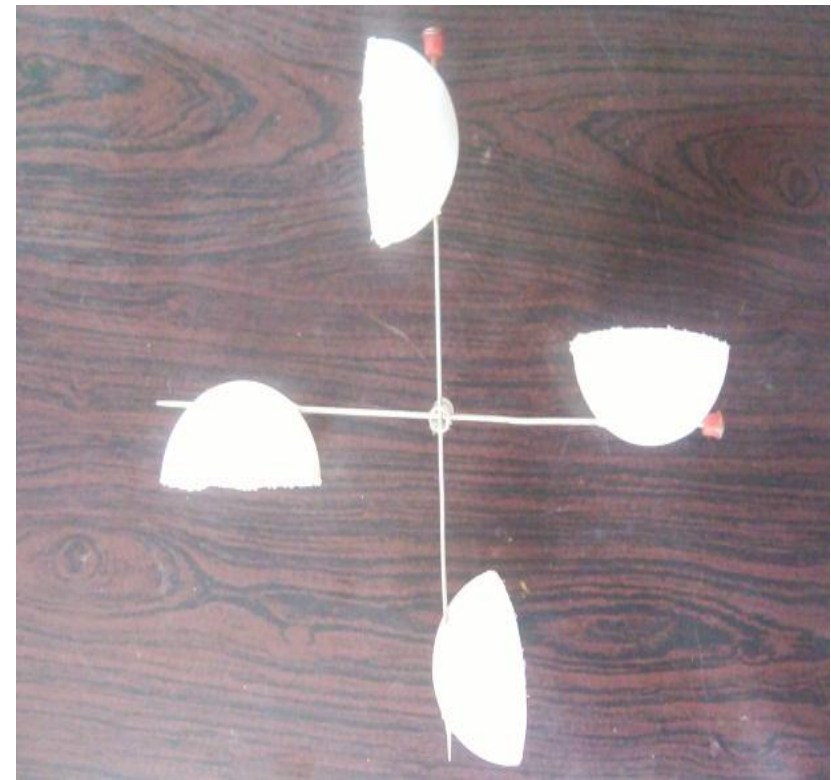

Fig. 1 Assembling of 4 Cup for 4 Cup anemometer 


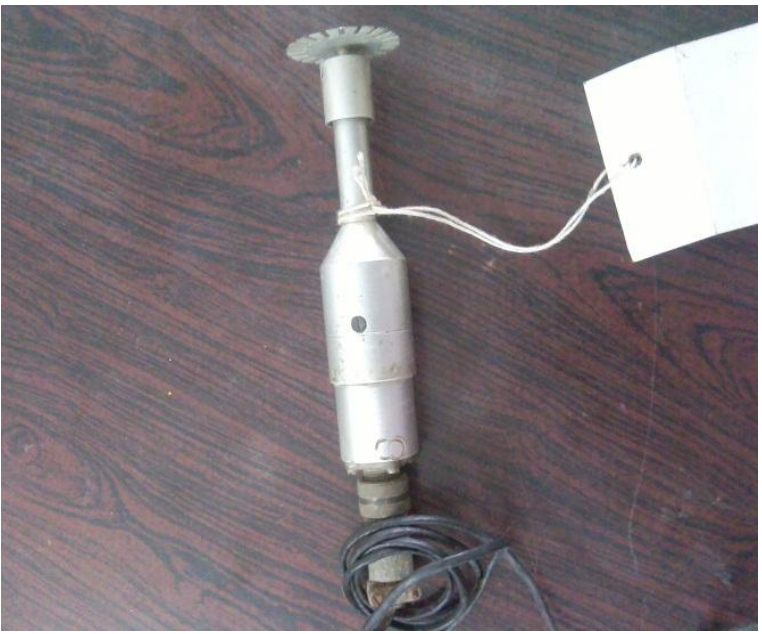

Fig. 2 Scrap Rotor with internal reed switch assembly

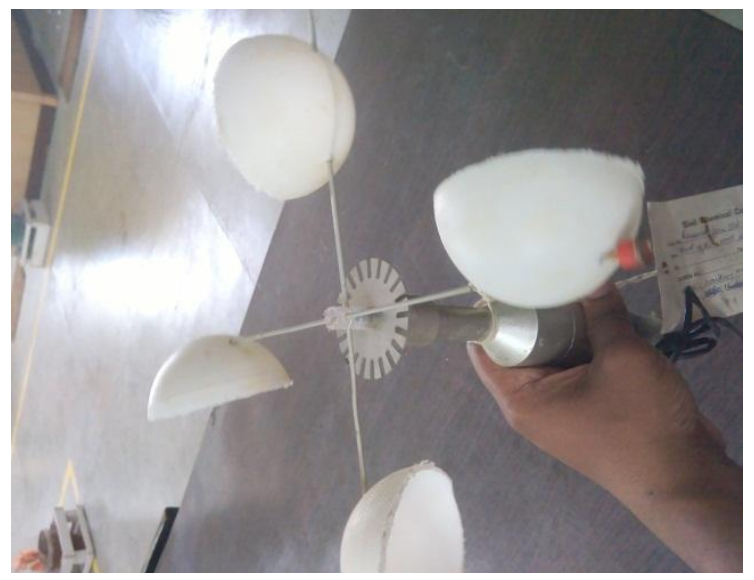

Fig. 34 Cup anemometer

This anemometer is highly responsive and has a low threshold for its starting (due to good quality of scrap rotor). A train of square wave whose frequency is directly proportional to the wind speed is obtained as output, which is further processed by frequency to current converter, and this signal is through wires to data loggers.

Table 1: Wind cup anmeometer specifications

\begin{tabular}{|l|l|l|}
\hline S.no & Various parts & $\begin{array}{l}\text { Material of } \\
\text { construction }\end{array}$ \\
\hline 1 & Cups & $\begin{array}{l}\text { Light weight } \\
\text { rugged plastic } \\
\text { cups }\end{array}$ \\
\hline 2 & $\begin{array}{l}\text { Horizontal rods for } \\
\text { cups }\end{array}$ & Aluminum \\
\hline 3 & Vertical shaft & Copper shaft \\
\hline 4 & Shaft bearings & Teflon \\
\hline 5 & sensor & $\begin{array}{l}4 \text { cup rotor } \\
\text { with magnet } \\
\text { and reed } \\
\text { switch }\end{array}$ \\
\hline 6 & Cup diameter & 60 mm \\
\hline 7 & Power supply & 5 Volt \\
\hline
\end{tabular}

\begin{tabular}{|l|l|l|}
\hline 8 & accuracy & $\begin{array}{l}2 \% \text { at full } \\
\text { scale }\end{array}$ \\
\hline 9 & Threshold & $0.3 \mathrm{~m} / \mathrm{s}$ \\
\hline
\end{tabular}

\subsection{Wind Vane}

The wind vane (e.g. Fig. 4) is used is for measuring wind direction. It consists of a light weight fin at its end made from light weight material like aluminum attached at one end of an aluminum rod and the other end is counter balanced by bob. This aluminum rod is balanced and connected to a vertical shaft that in turn is attached to transducer. The transducer here is a 360 degree turn precision potentiometer mounted on bearings, which provides negligible resistance to rotation. Here also transducer and bearings are protected by use of cover which rotates with vane.

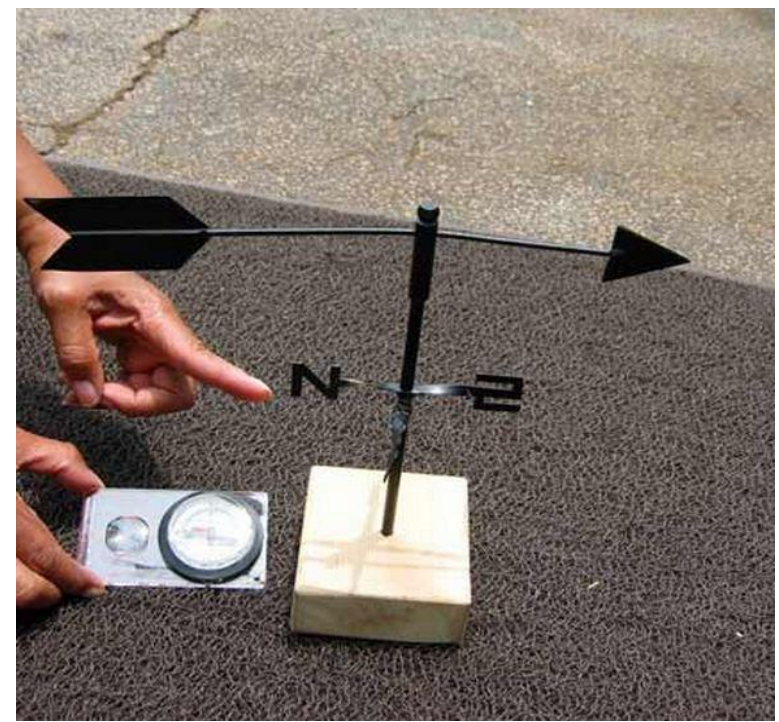

Fig. 4 Wind vane

1) Working of wind vane: The vane here constantly seeks the equilibrium position by aligning itself in the direction such that bob attached to it points to the direction of ongoing wind. Here potentiometer is $10 \mathrm{k} \Omega$ pot that gives an output in form of electrical signal relative to the position of vane (reference point, here its True north). This electrical signal is transmitted to data logger that converts it into the readable form as; data logger gives a known voltage across the whole pot element and measure the voltage where the wiper arm contacts a conductive wire element. The ratio of two helps in determine the actual wind direction.

Every potentiometer has a dead band, which is an open area in potentiometer conductive element where readings may fluctuate drastically. It happens when a rotation from 0 to 360 degree is made. Here dead band is 5 degree far better than other instruments. Here 360 degree is divided in such a way that we get output of 0-1 Volt for 0-360 degree rotation.

This design is reliable, accurate, low maintenance required and has a good response. 
Table 2: Wind vane specifications

\begin{tabular}{|l|l|l|}
\hline S.no & Various parts & $\begin{array}{l}\text { Material of } \\
\text { construction } \\
\text { specification }\end{array}$ \\
\hline 1 & Sensor & $\begin{array}{l}\text { Potentiometer } \\
10 \mathrm{k} \Omega\end{array}$ \\
\hline 2 & Range & $0^{\circ}$ to $360^{\circ}$ \\
\hline 3 & Accuracy & $2^{\circ}$ \\
\hline 4 & $\begin{array}{l}\text { Operating } \\
\text { temperature }\end{array}$ & $0^{\circ} \mathrm{C}$ to $50^{\circ} \mathrm{C}$ \\
\hline 5 & output & $\begin{array}{l}\text { Resistance } \\
\text { variation }\end{array}$ \\
\hline 6 & Fin & aluminum \\
\hline 7 & bob & steel \\
\hline
\end{tabular}

Here table 2 specifies material of construction and specified range for various parts used in wind vane designing.

\subsection{Temperature Probe}

Platinum Resistance temperature detector (PRTD 100) is used as sensor, which has a resistance of $100 \Omega$ at $0^{\circ} \mathrm{C}$. Connections of wiring is done to the 3 wire- RTD (e.g. Fig. 5), which provides internal auto-compensation to temperature changes. The resistance change of RTD due to ambient air change is measured with the help of digital controller by use of $230 \mathrm{~V}$ ac. This controller is capable of showing both resistance as well as temperature in its display. The electronics components in it provide conditioning that such that output vary from 0 to $5 \mathrm{~V}$ for temperature change of 0 to $50^{\circ} \mathrm{C}$. RTD bit is protected from direct sun rays of light with help of can with a holes in it and coated black inside and reflecting material or white painted at outside. We may also use professional gill shield from market, but it will be costly.

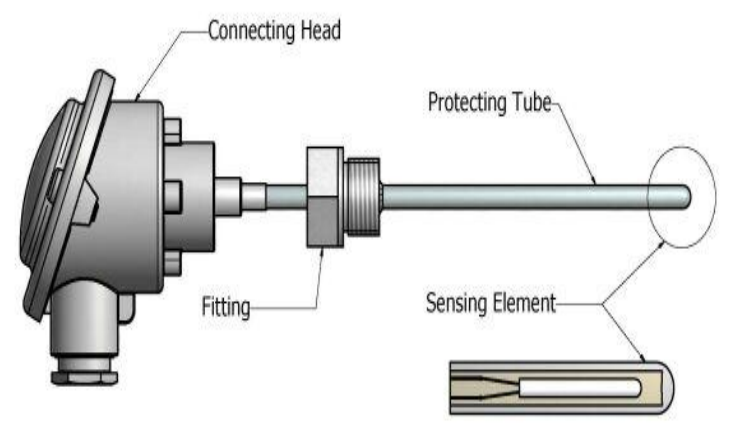

Fig. 5 Resistance Temperature detector[7]
Table 3: Temperature probe specifications

\begin{tabular}{|l|l|l|}
\hline S.no & Various parts & $\begin{array}{l}\text { Material of construction } \\
\text { / specification }\end{array}$ \\
\hline 1 & Sensor & RTD ( PT 100) \\
\hline 2 & Range & $0^{\circ} \mathrm{C}$ to $50^{\circ} \mathrm{C}$ \\
\hline 3 & Accuracy & $<0.5^{\circ} \mathrm{C}$ \\
\hline 4 & Resolution & $0.1^{\circ} \mathrm{C}$ \\
\hline 5 & Radiation shield & $\begin{array}{l}\text { Non aspirated radiation } \\
\text { shield Can }\end{array}$ \\
\hline 6 & Output & $\begin{array}{l}0 \mathrm{~V} \text { to } 5 \mathrm{~V} \text { for } 0^{\circ} \mathrm{C} \text { to } 50^{\circ} \\
\mathrm{C}\end{array}$ \\
\hline 7 & Power supply & $230 \mathrm{~V}$ ac \\
\hline
\end{tabular}

Here table 3 specifies the material of construction and range for RTD (PT 100)

\section{CALCULATION}

\subsection{Wind Speed}

The anemometer shaft is connected to the reed switch, which makes and breaks connections to generate a square pulse; its frequency is calculated by the frequency to current converter (e.g. Fig. 7).

Basic calculations are shown here, that will assist how internal software of data logger performs the calculations.

Revolution per minute (RPM) is obtained with help of frequency to current converter (e.g. Fig. 7), and radius of anemometer arms will help to obtain the speed as:

\section{Circumference, $\mathrm{C}=2 \pi \mathrm{r}$ in units of $\mathrm{cm}$}

$\mathrm{K}=$ correction constant

Distance in $\mathrm{km} / \mathrm{hr}=\mathrm{K} \times \mathrm{C} \times \mathrm{RPM} \times 60 \times(1 / 100000 \mathrm{~km} / \mathrm{cm})$ in units of $\mathrm{km} / \mathrm{hr}$

Table 4: Output table for wind speed

\begin{tabular}{|l|l|l|l|}
\hline S.no & $\begin{array}{l}\text { Frequency } \\
(\mathbf{R P M} / \text { 60) }\end{array}$ & $\begin{array}{l}\text { Current } \\
(\mathbf{m A})\end{array}$ & $\begin{array}{l}\text { Speed( } \\
\mathbf{k m} / \mathbf{h r})\end{array}$ \\
\hline 1 & 0 & 4 & 0 \\
\hline 2 & 27 & 8 & 26.3 \\
\hline 3 & 54 & 12 & 52.7 \\
\hline 4 & 81 & 16 & 78.9 \\
\hline 5 & 108 & 20 & 105 \\
\hline
\end{tabular}

Here table 4 shows the real time parameters measured by 4 cup anemometer by, and relating frequency, current and speed corresponding to the values.

\subsection{Wind Direction}

The wind vane shaft is connected to transducer $(10 \mathrm{k} \Omega$ potentiometer) for measuring the accurate position of vane with respect to reference point, thus concluding the accurate 
direction of wind. The potentiometer used here is $360^{\circ}$ type, with no rotational stop but have a dead band of $5^{\circ}$.

The wind vane is connected to the wiper of potentiometer, whose position with respect to reference point gives wind direction. The ends of potentiometer is fed to $0 \mathrm{~V}$ and $+5 \mathrm{~V}$ $\mathrm{DC}$, and then the wiper voltage varies as 0 to $+5 \mathrm{~V}$ for a difference of $0^{\circ}$ to $360^{\circ}$ when compared with reference.

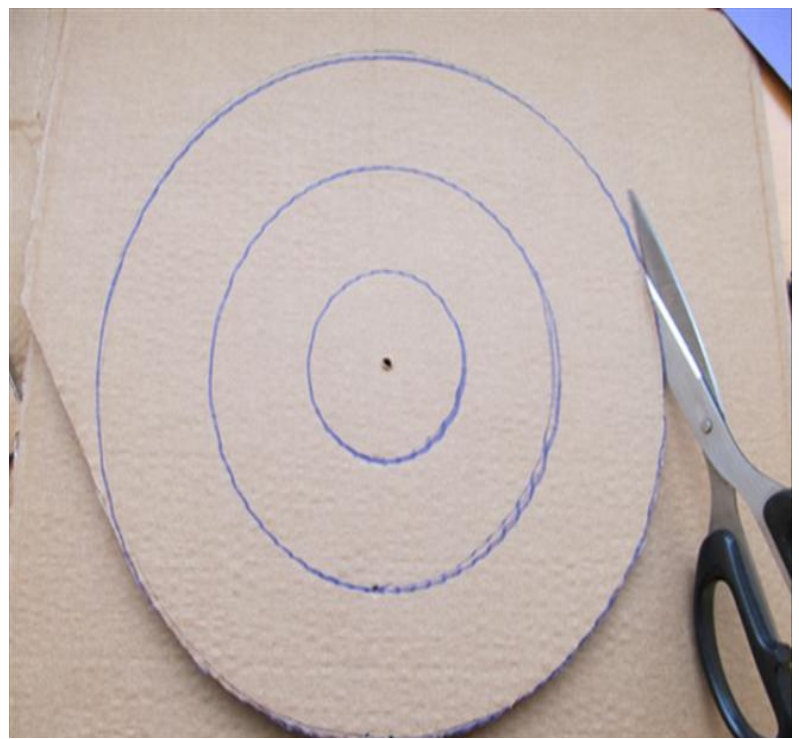

Fig. 6 Making rough compass by cardboard

The relation between wiper output voltage and indicated wind direction is as follow:

Wind direction $($ in degree from reference point $)=$

(Actual output voltage / applied voltage ) *360

1) Wind Direction calibration: In order to calibrate the vane, a circle is cut from the card board and a hole is punched inside it, and markings are drawn as per the directional compass (e.g. Fig. 6). .Good quality compass helps in making north as a Reference point, means at this position value of potentiometer reading should be zero. This is done manually by movement of vane in north direction and adjusting the potentiometer such that reading is zero. Then insert the card board across vane shaft such that north of original compass coincides the cardboard one, and move the vane manually in east, south and then west .Note the reading for each and conclude the result:

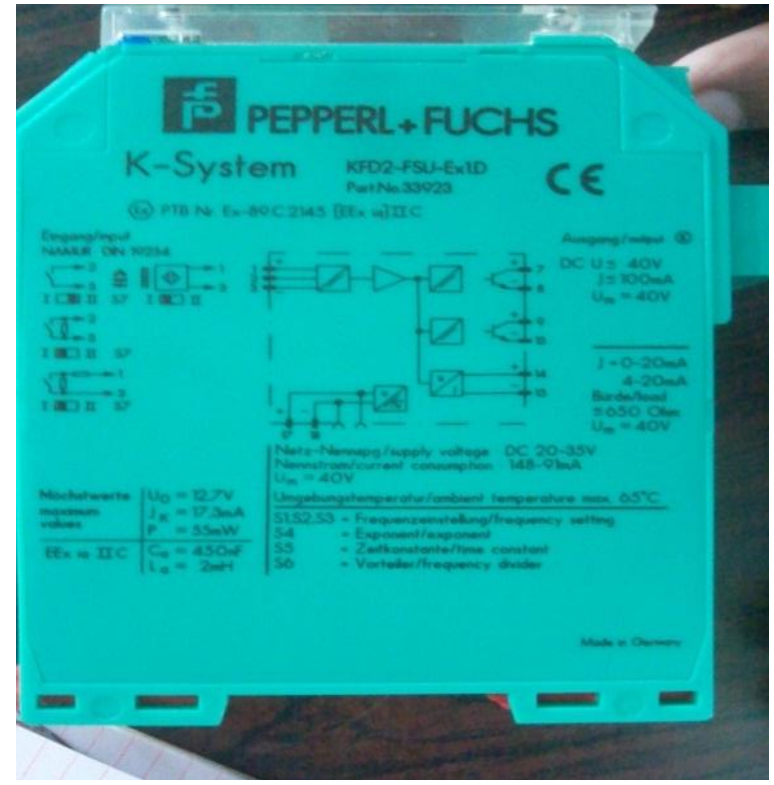

Fig. 7 Pepperl Fuchs KFD-FSU-ExID Frequency to Current converter

Table 5: Relation between angle and output voltage

\begin{tabular}{|l|l|l|l|l|}
\hline $\begin{array}{l}\text { S.n } \\
\text { o }\end{array}$ & $\begin{array}{l}\text { Angle } \\
\text { in } \\
\text { degree }\end{array}$ & $\begin{array}{l}\text { Direction } \\
\text { (N-North } \\
\text { S-South } \\
\text { E-East } \\
\text { W-West) }\end{array}$ & $\begin{array}{l}\text { Calculated } \\
\text { Output } \\
\text { Voltage } \\
\text { (volts) }\end{array}$ & $\begin{array}{l}\text { Actual } \\
\text { Output } \\
\text { Voltage } \\
\text { (volts) }\end{array}$ \\
\hline 1 & 0 & N & 0 & 0.2 \\
\hline 2 & 45 & NE & 0.625 & 0.65 \\
\hline 3 & 90 & E & 1.25 & 1.24 \\
\hline 4 & 135 & SE & 1.875 & 1.87 \\
\hline 4 & 225 & SW & 3.125 & 3.11 \\
\hline 5 & 270 & W & 3.75 & 3.77 \\
\hline 6 & 315 & NW & 4.375 & 4.38 \\
\hline 7 & $\mathbf{3 5 5}$ & & $\mathbf{4 . 9 3}$ & $\mathbf{1 . 8}$ \\
\hline 8 & 405 & NE & 0.625 & 0.61 \\
\hline
\end{tabular}

Table 5, provides the theoretical and practical measurement for wind direction, the angle and the voltage output of potentiometer.

\subsection{Temperature Probe}

Ambient temperature is measured with the RTD. RTD is connected to the indicator that holds internally relation between resistance measured and temperature in ${ }^{\circ} \mathrm{C}$.

1) Calibration of RTD: Here Whether the RTD is working correctly is checked by taking it into the three different process liquid where RTD was used and comparing the resistance.

Else one may use Ice Bath Calibration, Fluid bath calibration etc.

Display unit used is from Intelligent Sensor Meter (e.g. Fig. 8 and 9). Here we select parameters (e.g.TABLE 6) input type as $\mathrm{Pt}$, alarms as per choice, upper and lower limit 0 and 50 respectively, set point as 29 . 
Table 6: Below table shows industrial technical specifications for intelligent system meter mode: ui [8]

\begin{tabular}{|c|c|c|c|c|c|}
\hline Power supply: & 90-260V AC 5060 Hz $(+1 \cdot 10 \%)$ & WPUT TYPE & MEASURMG RANGE & INPUT IMPEDANCE & $\begin{array}{l}\text { FACTORY } \\
\text { BETIIIS }\end{array}$ \\
\hline & & A(WDA) & $A C 0.5 A / 0.20 A$ & CT conflgurable & $0.5 A$ \\
\hline Power consumption: & S5VA & $\mathrm{mA}$ & $0-1 \mathrm{~mA} / 0-10 \mathrm{~mA} / 4-20 \mathrm{~mA}$ & $\$ 150 \Omega$ & $4 \cdot 20 \mathrm{~mA}$ \\
\hline Aceuracy: & 10.3\% F.S (under normal conditons) & V(AVIDY) & $0.5 \mathrm{~V} / 0.10 \mathrm{~V} / 0.500 \mathrm{~V}$ & $\$ 200 \mathrm{~K} 0$ & $0 \times 10 \mathrm{~V}$ \\
\hline \multirow{3}{*}{ Bampling rate: } & \multirow{2}{*}{ cotmesis } & $\mathrm{mV}$ & $0-10 \mathrm{mV}( \pm 100 \mathrm{mV})$ & $\$ 2 M Q$ & $0.75 \mathrm{mV}$ \\
\hline & & Rit & $0-4000 / 10-10 \mathrm{~K}$ & $50.2 \mathrm{~mA}$ & 0.4000 \\
\hline & & & $0.1 \mathrm{~K} / 0.50 \mathrm{~K}$ & S0.1mA & \\
\hline \multirow[t]{2}{*}{ Inpot: } & \multirow[t]{2}{*}{ See input signals } & Dt & $.200-650 \mathrm{C}$ & & Droco \\
\hline & & $\mathrm{H}$ & CLSOCu100.50-150 C & $90.2 \mathrm{nA}$ & PIIOU \\
\hline \multirow{2}{*}{ Alarm output: } & \multirow{2}{*}{$\begin{array}{l}\text { Relay. NO contect capecty. } \\
\text { AC 250V BA or DC 3OV /3A Coesp:1 }\end{array}$} & \multirow{7}{*}{ TC } & $K: 0.1320 \mathrm{C}$ & \multirow{7}{*}{$S 2 M Q$} & \multirow{7}{*}{ K } \\
\hline & & & $\mathrm{J} .0 .1300 \mathrm{C}$ & & \\
\hline \multirow{2}{*}{ Analog output: } & \multirow{2}{*}{ 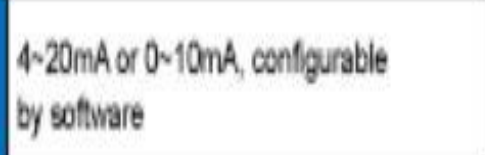 } & & $\mathrm{E}: 0.1000 \mathrm{C}$ & & \\
\hline & & & $T .150-4000 \mathrm{C}$ & & \\
\hline \multirow{3}{*}{ Transmilter supply } & \multirow{3}{*}{ Isolated DC 24V/30mA or DC 12V/30mA } & & B. $0.1820 \mathrm{C}$ & & \\
\hline & & & R: $0-1700 \mathrm{C}$ & & \\
\hline & & & s: $0 \times 1600 \mathrm{C}$ & & \\
\hline Communicatlon: & $\begin{array}{l}\text { RS485 or RS232 inteface } \\
\text { (Modbus protocol) }\end{array}$ & Pr & \multicolumn{2}{|c|}{20 segments cutomized linetar input } & $\begin{array}{l}\text { Indcate } \\
\text { when order }\end{array}$ \\
\hline
\end{tabular}

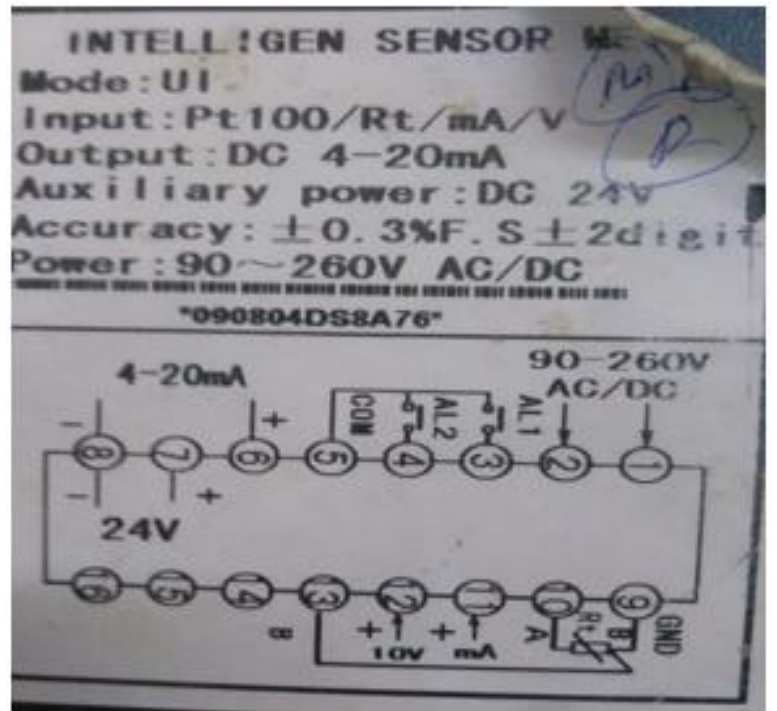

Fig. 8 Electrical connection drawing

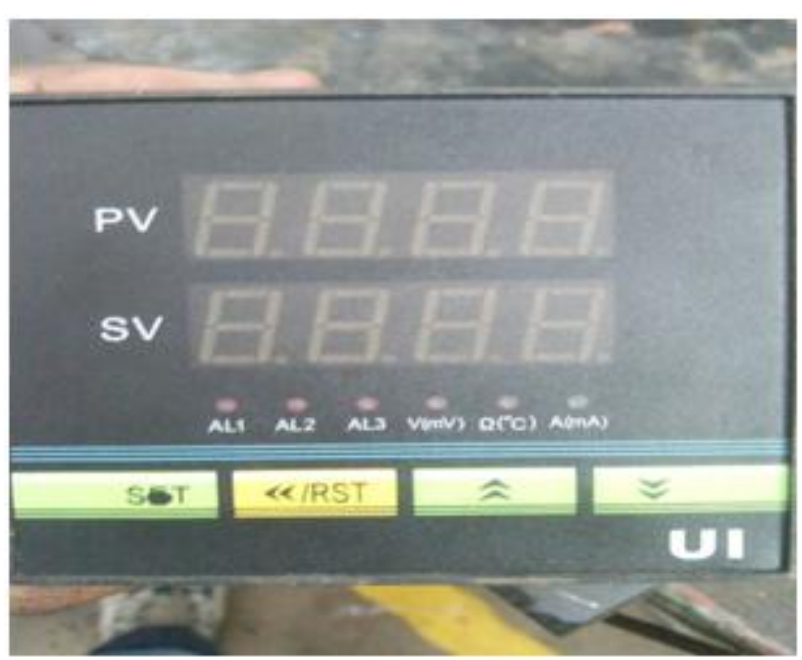

Fig. 9 Front Panel of Intelligent sensor meter 


\section{RESULTS AND DISCUSSION}

The proposed system here is a low cost, well calibrated, accurate, and optimized system. It utilizes scrap items like rotor of an old machine, plastic cups, aluminum rods, and other low cost components such as Controller (Intelligent system meter) as display unit, RTD bit.

down The result obtained are accurate as per the cost and this proposed project can be installed in any industry where speed and direction are major factor that needs to be monitored to prevent disaster from happening.

The readings shown (e.g. Fig. 9, 12) are compared with the previously installed wind monitoring system by Sunshine enterprises. We here notice that cost factor has come many folds without comprising with the accuracy.

\section{COST COMPARISON}

There was a big difference between the costs it costs us almost 18000 rupees, in comparison to 1.5 lakhs. (e.g. Table 7)

Table 7: Below table 7 shows the cost of some components used in designing of project

\begin{tabular}{|l|l|l|}
\hline S.no & parts & price \\
\hline 1 & Cups & 30 \\
\hline 2 & Rods & 20 \\
\hline 3 & Display & 4000 \\
\hline 4 & F to I & 8000 \\
\hline 5 & Potentiometer & 2500 \\
\hline 6 & adapter & 80 \\
\hline 7 & wiring & 600 \\
\hline
\end{tabular}

\section{CONCLUSIONS}

The focus of this paper is in designing a low cost and yet optimized wind monitoring system. The most important conclusion that are extracted from this project are:

1) It is cost effective as it reduces the cost many folds as compared to the cost if we buy whole accessory from one vendor.

2) Small industries that do not feel necessary, the use of wind monitoring system, and were dependent on others, can have it at low cost.

3) Since it utilizes scrap material and other self-made components it helps engineer to develop and expand their thought process to achieve the desired result that too in confined limits.

4) Here many components as controller unit, RTD were used from outside vendor; one learns to use money efficiently to have the desired result at minimum cost.

5) Since we had all it calibrated and tested manually once, these controller are then attached to transmitter which correspondingly sends data to DCS, and thorough records can be maintained similar to that, if we had purchased it all from vendor.

6) Since it is a kind of assembling, we here pays no extra cost to vendor for the features that we not require, as here we do not want humidity measurement, so we did not have it that saved us money.

7) Accuracy, reliability are well maintained in this process as verified from the data.

\section{REFERENCES}

[1]. Marc Schwartz, Dennis Elliott, Dave Blittersdorf, Ken Cohn, Rich Simon, Jack Kline "Wind resource assessment handbook", AWS scientific Inc. April 1997

[2]. Dr. Fouad Sh. Tahir , Ayad M. Salman, "Data Acquisition System for Wind Speed, Direction and Temperature Measurements", Number 11 Volume 18 November 2012 Journal of enginnering.2012

[3]. D.C. Anderson, J. Whale, P.O. Livingston, "Rooftop Wind Resource Assessment using a Three-Dimensional Ultrasonic Anemometer", ontario-sea.org. May 2008

[4]. William David Lubitz, "Effects of Tower Shadowing on Anemometer Data", 11th Americas Conference on Wind Engineering.

[5]. Hughes, P.A (1986) Validation of a model for thermal emission, Durham theses, Durham University.

[6]. Raymond S Hunter, "Wind speed measurement and use of cup anemometry", Renewable Energy Systems Ltd.

[7]. http://www.instreng.com/2-wires-3-wires-or-4-wiresrtd-resistance-temperature-detector/

[8].http://www.sanyoutech.com/UploadProductPic/2009917 1524682683.pdf

[9]. E.Annie Elisabeth Jebaseeli, "Real Time Temperature Measurement for the Thermal protection of Switched Reluctance Machine", International Journal of Engineering \& Technology (0975-4024); Jun/Jul2013, Vol. 5 Issue 3, p2983

[10]. Sunshine enterprises, wind monitoring system.

\section{BIOGRAPHIES}

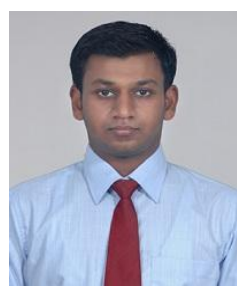

Name: Saurav Gupta

E-mail: sauravg969@gmail.com

Current Position: B.E. Student in

Electronics and Instrumentation Control

Engineering, Thapar University, Patiala.

Expert areas: Process control, plc

programming.

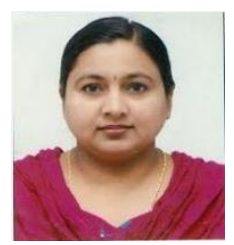

Name: Dr. Gagandeep Kaur

E-mail: gagandeep@thapar.edu

Current Position: Assistant Professor in

Electrical and Instrumentation

Department, Thapar University, Patiala.

Paper published: $45+$

Expert areas: Artificial Intelligence and control engineering. 
